\title{
Announcement
}

\section{Bibliometrics / information retrieval conference 1987}

The First International Conference on Bibliometrics and Theoretical Aspects of Information Retrieval will be held at the Limburgs Universitair Centrum (LUC), Belgium, from 25 through 28 August 1987. The Organizing Committee for this conference consists of: A. Bookstein (University of Chicago), B.C. Brookes (University College London), R.V. Ravichandra Rao (Indian Statistical Institute, Bangalore), L. Egghe (LUC), and R. Rousseau (Universitaire Instelling Antwerpen).

If you wish to be kept informed concerning this conference, and to receive a copy of the Call for Papers, please send your name and address to:

Prof. Dr. L. Egghe

LUC

Universitaire campus

3610 Diepenbeek

Belgium 